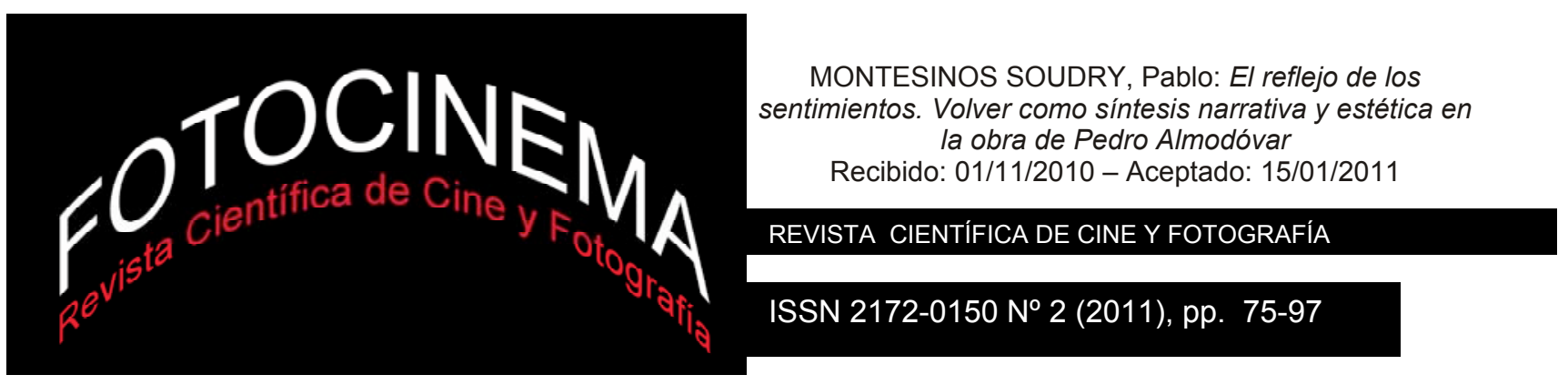

\title{
EL REFLEJO DE LOS SENTIMIENTOS. VOLVER COMO SÍNTESIS NARRATIVA Y ESTÉTICA EN LA OBRA DE PEDRO ALMODÓVAR
}

\author{
REFLECTING EMOTIONS: VOLVER, A NARRATIVE AND \\ AESTHETIC COMPENDIUM IN ALMODOVAR'S FILMOGRAPHY
}

\author{
Pablo Montesinos Soudry \\ Universidad de Málaga
}

\section{Resumen:}

La obra cinematográfica de Pedro Almodóvar ha experimentado una gran evolución, que tiene que ver, sobre todo, con un mayor dominio de la narrativa cinematográfica $\mathrm{y}$ un progresivo refinamiento de la estética. Y sin embargo, se puede señalar claramente una serie de temas, personajes, rasgos narrativos y estéticos comunes y constantes en la filmografía del director manchego. Todos ellos se encuentran presentes en su película Volver (To Retun, 2006), que resulta un compendio y una reelaboración del imaginario y de los referentes temáticos repetidos a lo largo de toda su filmografía, y, sobre todo, una culminación de las pautas narrativas y estéticas definitorias de su obra. Esta película será utilizada como instrumento de privilegio para evaluar cómo los responsables de la fotografía, el vestuario y el diseño de producción trabajan bajo las órdenes del director para lograr unos resultados tan específicos de este autor.

\begin{abstract}
:
The Pedro Almodovar film work has evolved greatly, which deals mainly with a greater mastery of narrative film and a progressive refinement of the aesthetic. And yet, you can clearly identify a number of themes, characters, narrative and aesthetic features common and constant in the films of Almodóvar. All of them are present in the film Volver (To Retun, 2006), which is a compendium and a reworking of the imagery and themes repeated throughout his filmography, and, above all, a culmination of the narrative patterns and defining aesthetic of his work. This film will be used here as a privileged instrument to assess how those responsible for photography, costumes and production design work under the orders of the director to achieve the personal touch of this auteur.
\end{abstract}

\section{Palabras clave:}

Pedro Almodóvar; Volver; rasgos estéticos; pautas narrativas

Key words:

Pedro Almodóvar; To Retun; aesthetic features; narrative patterns 
Pedro Almodóvar, el artista que hoy es admirado y premiado en todo el mundo, es autor de sus películas y también de su propio personaje: su actitud resulta escandalosa para una parte de la sociedad de la época en la que inicia su carrera, y eso convierte sus películas en éxitos y a él mismo en el representante de la modernidad en la España que sale de la dictadura franquista con deseos de convertirse en otra cosa.

Cuando Almodóvar empieza a difundir sus obras, ya se puede considerar que la transición política española está en sus últimos momentos, pero el cine español mantenía muchas similitudes temáticas y narrativas con respecto a épocas anteriores. Resulta lógico que los cineastas que habían comenzado su actividad antes de los años ochenta ${ }^{1}$ mantuvieran planteamientos clásicos en sus películas. Pero la actividad cinematográfica de estos nuevos creadores tampoco genera formas cinematográficas innovadoras.

Aunque sus películas se reflejan las formas de vida generadas en su entorno más cercano; la mayor parte de los directores españoles más jóvenes asumen los géneros establecidos. De hecho, uno de los elementos más característicos del cine de estos profesionales es el componente costumbrista, que tan claramente había caracterizado la comedia española en décadas anteriores. Surge así, por ejemplo, con presupuestos pequeños, la denominada comedia madrileña ${ }^{2}$. Los argumentos de enredo de estas películas, en la línea de la comedia clásica norteamericana, suelen incluir frecuentes referencias locales. Los intérpretes de estos títulos son una nueva generación de actores sin relación con épocas anteriores: se puede mencionar, por ejemplo, a quienes serán también dos chicas Almodóvar, Carmen Maura y Verónica Forqué...

En definitiva, entre los directores más jóvenes, sólo el autor que es objeto de este estudio parece romper radicalmente con tradiciones anteriores. Y, sin

${ }^{1}$ Luís García Berlanga, por ejemplo, se mantiene plenamente activo durante los años ochenta. Además, el cineasta obtiene dos de los éxitos comerciales más importantes de la década con Patrimonio nacional (National Heritage, 1981), que satiriza a la España franquista a través de una familia, los Leguineche, y La vaquilla (The Heifer, 1985), la única comedia importante que evoca la memoria de la Guerra Civil Española.

${ }_{2}^{2}$ Significativamente, denominada en un primer momento "comedia costumbrista madrileña”. 
embargo, a pesar de esta apariencia, el cine de Almodóvar tiene algunas similitudes con el de sus compañeros de generación: también él se centra en el paisaje urbano de Madrid, como Fernando Trueba o Fernando Colomo. Lo mismo que estos directores, Almodóvar considera el cine clásico americano como uno de sus referentes narrativos, aunque su ejemplo son más los melodramas de Douglas Sirk que las comedias, como ocurre con sus compañeros de generación. Y, por supuesto, sus películas son el resultado de la tradición cinematográfica española: el reflejo de las formas de vida y la estética populares que aparece en sus comedias constituye una puesta al día de la tradición esperpéntica que definen Berlanga o Fernando Fernán Gómez a partir de los años cincuenta. En definitiva, también el heterodoxo Almodóvar es un producto de la Historia del cine español.

Con este punto de partida, la obra cinematográfica de Pedro Almodóvar ha experimentado una gran evolución, que tiene que ver, sobre todo, con un mayor dominio de la narrativa cinematográfica y un progresivo refinamiento de la estética. Hay una transformación evidente desde sus primeras películas situadas en el contexto de la movida madrileña hasta una última etapa de obras, en cierta forma, autoreflexivas. $\mathrm{Y}$ sin embargo, se puede señalar claramente una serie de temas, personajes, rasgos narrativos y estéticos comunes y constantes en la filmografía del director manchego. Características habituales que son precisamente las que permiten atribuir a Pedro Almodóvar la categoría de autor cinematográfico, es decir, de cineasta con ideas, inquietudes y un lenguaje cinematográfico propio y original. En cierta forma, se puede ver Volver (To Retun, 2006) como un compendio y una reelaboración del imaginario y de los referentes temáticos repetidos a lo largo de toda su filmografía, y, sobre todo, como una culminación de las pautas narrativas y estéticas definitorias de su obra.

Volver servirá aquí como eje para analizar la obra de Almodóvar desde una perspectiva algo distinta a la que suele ser habitual en la abundante bibliografía existente acerca del autor. Se tendrán en cuenta, en primer lugar, los hallazgos narrativos del cineasta, que demuestra una capacidad casi intuitiva para mezclar géneros cinematográficos, y como esta característica determina la 
planificación y la puesta en escena de sus películas. Además, se estudiará la estética característica del universo de Pedro Almodóvar. Personal, colorista, sofisticada, urbana, pop, y kitch son los adjetivos que mejor definen uno de los elementos más identificativos de las películas de este director. En este sentido, Volver será utilizado como instrumento de privilegio para evaluar cómo los responsables de la fotografía, el vestuario y el diseño de producción trabajan bajo las órdenes del director para lograr unos resultados tan específicos.

\section{El cine de Almodóvar, ¿un género en sí?}

Vicente Molina Foix considera que el cine de Pedro Almodóvar "no es ni drama, ni telenovela, ni melodrama, sino algo que nace y muere en sí mismo" (Molina Foix, 1993: 103). De hecho, este autor inventa un neologismo para denominar la obra del director manchego, el de “almodrama”. Quizá se trate simplemente de un vacío término ingenioso, pero resulta significativo de la profunda especificidad que define las películas de este director.

El cine de Almodóvar se caracteriza por una mezcla de elementos reales e irreales, pero la irrealidad que marca su filmografía debe entenderse como artificio, y no como fantasía. No se trata de que en las películas que realiza Pedro Almodóvar a partir de Pepi, Luci, Bom y otras chicas del montón (Pepi, Luci, Bom and Other Girls Like Mom,1980) convivan la realidad más inmediata y un universo paralelo. Tampoco se puede decir que el concepto almodovariano del cine suponga una hiperbolización de la realidad hasta convertirla en algo fantástico, como ocurre en la filmografía más característica del italiano Fellini.

Más bien, se trata de una convivencia de elementos, situaciones y personajes realistas con otros artificiosos. Esta mezcla de elementos tan distintos en un mismo plano narrativo crea en el espectador una conciencia mayor del relato que en una película convencional. Sin embargo, este director llega a conseguir que la acumulación de situaciones y de personajes improbables 
resulte verosímil para el espectador y que éste se identifique con lo que está viendo y lo viva, sin preocuparse de si es real.

En las películas de Almodóvar, parece normal que una abuela procedente de un pueblo mantenga la mejor de las relaciones con su nieto traficante de droga, como ocurre con el personaje que interpreta Chus Lampreave en ¿Qué he hecho YO para merecer esto! (What Have I Done to Deserve This?, 1984). Un claro ejemplo de cómo lo improbable puede parecer verosímil en las películas de este director es el tono realista que caracteriza la interpretación de esta veterana actriz tan significativa del universo almodovariano, y que interviene tanto en el título citado como en otras películas anteriores y posteriores del director ${ }^{3}$.

Habitualmente, la inclusión de una película en un género determina unos límites y unas rutas habituales en la narración. Se establece una suerte de código común por el que el espectador espera y acepta un tipo de personajes y de giros narrativos y no otros. Este pacto se rompe en las películas de Almodóvar. Para Fran A. Zurián, el motivo es que “algunas veces, Almodóvar (...) lo que hace es diseñar a sus personajes (...) de forma que en la misma película se mezclan géneros, los que aporta cada personaje" (ZURIAN, 2005: 28).

Ciertamente, hay casos en los que los personajes del director manchego se muestran a través de múltiples facetas. Y un ejemplo claro se percibe en el argumento de Volver: quizás no resulte extraño que un fantasma confiese que quemó una casa, como ocurre con Irene (Carmen Maura), pero que ese mismo fantasma se tire pedos o se tiña el pelo unas secuencias antes nos obliga como espectadores a "ver" a ese personaje con todas sus características específicas. En ningún momento pensamos que el comportamiento del personaje de Irene sirva para definir la última película de Almodóvar como

\footnotetext{
3 Chus Lampreave, que aparece también en Entre tinieblas (Dark Habits, 1983), Mujeres al borde de un ataque de nervios (1988) o Volver (2006), interpreta ya a personajes secundarios en las comedias realizadas por Berlanga o Ferreri en los años cincuenta en España. Marvin D'Lugo considera que "La presencia fortuita de Chus en las películas de Almodóvar conmemora la relación especial entre el director y las tradiciones de las comedias disidentes de los 50" (Lugo, 2004: 295).
} 
una historia de fantasmas. Y eso es lo ocurriría si la ordenación del material se llevara a cabo en los límites de una narración convencional.

La sucesión de escenas de thriller, escenas de comedia y escenas melodramáticas o costumbristas se produce en todas las películas de Almodóvar sin que exista separación alguna entre unos elementos y otros. Esta solución narrativa adoptada por el director manchego nos obliga como espectadores a salir de los conocidos límites de las estructuras del género. En definitiva, se podría decir, incluso, que la obra de este cineasta ha llegado a definirse como un género en sí misma. El mismo realizador expresa su concepción a este respecto en el diario de rodaje de Volver,

"Supongo que Volver es una comedia dramática. Tiene secuencias divertidas y secuencias dramáticas. Su tono imita "la vida misma”, pero no se trata de un film costumbrista. Pertenece más bien a un naturalismo surrealista, si se puede denominar así. He mezclado desde siempre los géneros y continúo haciéndolo; para mí es una operación del todo natural” (ALMODÓVAR, 2005).

Sin embargo, este planteamiento tan propio y tan original de la obra de Almodóvar tiene a veces contrapartidas negativas: la mezcla brusca de géneros puede derivar en desigualdades en el ritmo narrativo que son patentes, incluso, en sus mejores películas. Es el caso de Volver, dónde la necesidad de cambiar el registro narrativo de la comedia al drama origina ciertos desfallecimientos en el tono general. De todas maneras, no es el ejemplo más significativo: en la última película de Almodóvar cada género tiene su hueco, pero hay otras obras del director manchego, como puede ser el caso de Kika (1993), dónde las “piruetas genéricas” provocan más extrañeza que complicidad en el espectador.

Otro de los aspectos negativos de esta particularidad de la filmografía almodovariana es que, a veces, algunos de sus actores manifiestan una escasa flexibilidad interpretativa cuando se enfrentan a estos cambios de registro genérico. Un caso patente es el de Imanol Arias, habitualmente un actor muy eficaz, en La flor de mi secreto (The Flower of My Secret, 1995). Por el contrario, hay otros intérpretes que manifiestan una destreza especial para 
enfrentarse a este reto interpretativo sin perder la naturalidad. Es el caso de Carmen Maura, tanto en Volver como en cualquiera de los personajes que interpreta en las películas del director manchego. No en vano, se la considera una de las actrices más significativas en la filmografía de Almodóvar.

\section{El formato panorámico en Almodóvar; apropiación de un rasgo narrativo del cine clásico de Hollywood}

Pero, además de una cuidada dirección de actores, la concepción clásica de composición y movimientos de cámara también contribuye mucho a esta naturalidad en la mezcla de géneros. Almodóvar, gran admirador de los melodramas norteamericanos de los años 50, ha incorporado a sus obras la mayoría de los rasgos narrativos que definen estas producciones. En las películas dirigidas por el director manchego, se utilizan como referentes la fotografía y el color saturado característicos de las grandes producciones realizadas en Technicolor durante la etapa clásica de Hollywood. Pero también provienen de esta misma fuente las composiciones muy cuidadas que aprovechan el formato $\mathrm{Scope}^{4}, \mathrm{y}$ una planificación con pocos movimientos de cámara, siempre ligados a las pautas dramáticas establecidas en el texto.

Partiendo de esta influencia proveniente del cine estadounidense, hay que tener en cuenta también que uno de los rasgos narrativos más clásicos en la obra de Almodóvar, que se ha ido acentuando con el paso del tiempo, es el modo de componer la imagen horizontalmente aprovechando el formato panorámico 2'35:15. Abundan los planos medios de dos, tres o más

personajes que se distribuyen llenando el encuadre, y que se mantienen relativamente estables en la pantalla mientras los actores desarrollan sus partes del guión. Significativamente, Almodóvar no planifica los encuadres

\footnotetext{
4 Este formato también es conocido como "Panorámico" o 2’35:1, por su relación de aspecto entre los márgenes verticales y horizontales del encuadre. En los límites del marco que delimita la imagen recogida por la cámara, a cada unidad vertical corresponden 2'35 unidades horizontales.

5 Ya a partir de su segunda película, Laberinto de pasiones (Labyrinth of Passion, 1982), Pedro Almodóvar adopta este formato.
} 
utilizando lo que se denomina "términos", técnica compositiva habitual con formatos panorámicos. Este procedimiento, muy común, consiste en situar objetos o cualquier otro tipo de elemento visual, como el brazo de un actor, por ejemplo, en un lateral de la imagen. Estos elementos visuales se sitúan por delante de la zona en la que se mueven los personajes, generalmente fuera de foco, y cumplen dos funciones: reencuadrar la imagen y añadir significado a la imagen.

Aunque también recurre a esta técnica de composición explicada arriba, en el cine de Pedro Almodóvar, la composición de los planos suele estar al servicio de los actores. El director manchego deja que sean sus personajes los que llenen el cuadro, para se derive de ellos toda la significación de la secuencia. En definitiva, Almodóvar no suele utilizar "términos" para realizar los reencuadres, y centrar, así, la atención en los personajes o elementos que interesan para el transcurso narrativo. Es por eso que el uso de colores vivos en el vestuario de los personajes que aparecen en su cine sirve también para centrar la atención en las figuras humanas, además de cómo referente estético.

Sin embargo, Almodóvar también puede seguir las pautas más comunes en la composición de planos. En los momentos en los que Volver adopta las pautas thriller, para marcar el cambio respecto a las fases de drama o comedia, se utiliza un lenguaje audiovisual que puede considerarse dentro de las convenciones del género: movimientos de cámara que se inician sin personajes, o con angulaciones de cámara poco habituales. Un caso paradigmático en esta película es el del plano cenital del escote de Penélope Cruz (Raimunda) mientras lava el cuchillo con el que se cometerá el asesinato de su marido algunas secuencias después.

También hay que decir que, para recrear la tensión narrativa en estos momentos, el director sí recurre a los elementos desenfocados en primer término. Esta forma de composición se percibe en la secuencia de Volver en la que Sole (Lola Dueñas) sube al dormitorio de su tía Paula (Chus Lampreave). En este momento, un lento travelling que parte de un plano medio de la actriz, recorre un espacio vacío para acabar presentando al 
espectador una bicicleta estática. Este procedimiento retórico crea una mayor tensión narrativa, que acrecienta la sorpresa derivada del hallazgo de este objeto insólito en el dormitorio de una anciana.

Esta alternancia en el uso de pautas convencionales y conceptos propios en la composición de los planos no supone una ruptura con el uso de la narrativa clásica que antes se ha destacado como característica en el cine de Almodóvar. A semejanza de las películas norteamericanas que considera sus referentes, el realizador manchego no llega a cabo excesivos movimientos de cámara, que suelen ser fluidos y se justifican por el recorrido de los actores. Pero, apartándose de nuevo de las tendencias convencionales, Almodóvar no basa la creación de significados en los movimientos de cámara. Esta característica de la filmografía del director manchego se aparta de lo que suele ser habitual en el cine comercial actual: en la mayoría de las películas, el movimiento de la cámara delimita el espacio del actor y dialoga con él para la expresión del significado dramático ${ }^{6}$.

En la obra de Pedro Almodóvar, la norma general es dejar que los actores circulen por el espacio escénico delimitado por el encuadre panorámico. Los personajes casi siempre aparecen de dos en dos y desarrollan sus diálogos. La cámara los sigue cuando se desplazan por las habitaciones, cuando van a interactuar con un objeto o cuando se quiere subrayar el peso de la frase que el actor va a pronunciar a continuación. Un ejemplo se encuentra en la secuencia en la que Paula (Yohana Cobos) descubre el arcón frigorífico donde está el cadáver de su supuesto padre. Entonces, sube por una escalera de mano para clavar una guirnalda en el techo. En ese momento, Paula le pide explicaciones a su madre, Raimunda. Para añadir importancia al diálogo que va a ser pronunciado por Paula, la cámara realiza un movimiento cuyo recorrido y duración marcan un ritmo que añade peso dramático. Se trata de un travelling largo que se inicia por delante de Paula y termina en una grúa

\footnotetext{
${ }^{6}$ Como ejemplo reciente de este modo de entender el movimiento de cámara, podemos citar Los Otros (The Others, Alejandro Amenazar, 2001). En esta película, una gran parte del suspense está construido mediante travellings a la altura de la cadera que se anticipan al movimiento de la actriz principal.
} 
ascendente en ángulo algo contrapicado, que se justifica por la acción que está llevando a cabo el personaje.

El ejemplo anterior sirve para reiterar que Volver muestra un mayor uso de movimientos de cámara que otras películas anteriores de Pedro Almodóvar. En parte, este tipo de planificación se puede atribuir a la necesidad de adoptar las convenciones genéricas ya explicadas. Pero, además, se observa que Almodóvar, en su progresiva estilización del lenguaje narrativo, ha ido incorporando movimientos que antes no llevaba a cabo. Resultan novedosas las secuencias en las que Raimunda habla con Paula por la calle, rodadas casi como planos secuencias con steadycam y muchos figurantes. Este uso de la cámara confiere a su última película una mayor fluidez, aunque no la aparta del estilo de inspiración clásica que ha caracterizado su obra7, y tampoco aporta ningún cambio en la estética almodovariana.

\section{La planificación en Volver}

Volver consta de 109 secuencias, que se repartan en 42 secuencias rodadas en exteriores (27 de ellas de día y 15 de noche), y 67 secuencias de interiores, 40 con efecto día y 27 con efecto noche. A pesar de los resultados cuantitativos, hay que señalar que casi un tercio de las secuencias de exteriores son escenas de un único plano, cuya función es establecer la geografía cinematográfica, con coches que llegan, se van o atraviesan las carreteras manchegas plagadas de generadores eólicos, o planos generales del barrio o del hospital, también con el cometido de orientar al espectador sobre dónde se desarrolla la acción.

Es significativo como en estas secuencias de transición se hace un tratamiento de la estética distinto al de las escenas con diálogo y desarrollo dramático. Así, observamos que son secuencias con colores menos saturados,

\footnotetext{
$7 \mathrm{Al}$ respecto, afirma lo siguiente Jose Luis Alcaine, director de fotografía de Mujeres al borde de un ataque de nervios (Women on the Verge of a Nervous Breakdown, 1988), Átame (Tie my Up! Tie my Down!, 1989), La Mala Educación (Bad Education, 2004) y Volver: "Antes Pedro movía menos la cámara, ahora la mueve más, y en anamórfico los problemas aumentan. Hay que ir con un diafragma más grande, iluminar es más difícil y sacar guapa a Penélope Cruz también es más difícil.” (Durán, 2006).
}

84 
y con un uso más naturalista de la luz, generalmente luz de atardecer. Esta diferencia en el tratamiento fotográfico de las secuencias se puede deber a la mayor dificultad de iluminar o decorar una gran área para un plano muy general $^{8}$, pero probablemente tiene que ver con que Almodóvar delega mucho más en Alcaine, director de fotografía especializado en un estilo naturalista, simplemente porque no le interesan demasiado esas secuencias. Para el director manchego, el drama tiene lugar en los diálogos entre los actores, y la narración avanza con sus conversaciones y con las reacciones expresadas en sus miradas, y por lo tanto, es en estas secuencias donde Pedro Almodóvar despliega también toda su personal estética. Él mismo lo explica así en su diario de rodaje:

"Esta es una semana menos intensa, rodamos muchas de esas secuencias de compromiso con la verosimilitud con que los actores salen y entran de las casas, detienen los coches, los aparcan, etc. En una película todo es importante, pero a mí me pesan estas secuencias necesarias para ubicar la acción y establecer su geografía. En La Mancha también había puertas, pero allí la gente las deja abiertas, por lo que no interrumpían la acción sino que la hacían fluir. Estos planos de entradas y salidas de coches o viviendas son planos exigidos por la ortografía cinematográfica.”

También es muy personal el abundante uso que hace Almodóvar de los planos detalles, casi siempre rodados desde una posición cenital de cámara, como plano inicial de una nueva secuencia. Así, se observa que de 109 secuencias, 15 comienzan con un plano de este tipo. Este recurso sirve en la gramática audiovisual habitual para remarcar una elipsis espacio temporal, pero en Volver resulta característico no sólo por el número de veces que se emplea, sino porque en Almodóvar este tipo de planos adquiere mayor peso. Narrativamente, sirven para describir no sólo una elipsis, sino que frecuentemente sirven para delimitar el paso de una fase de la película desde un género a otro. Por ejemplo, después de una fase de comedia en la que Carmen Maura se esconde de Raimunda en la casa de Sole, con la

\footnotetext{
${ }^{8}$ Aunque este problema se puede solventar mediante el uso de filtros de color en cámara. Como ejemplo de una película colorista cuyo drama reside en planos muy generales coloreados mediante filtros, podemos citar la película de Bernardo Bertolucci The Sheltering Sky (El cielo protector, 1990)
} 
complicidad de esta y de Paula, se corta a un plano picado de un flan saliendo del molde, dando así comienzo a una conversación más dramática entre las dos hermanas. Hay que señalar que estos planos cenitales tienen una duración mayor de lo habitual, y esto hace que, cuando se encuadra un elemento con un peso narrativo dentro de la historia, se produzca casi un efecto poético, una metonímia de vivos colores que prepara al espectador para la secuencia a la que está dando paso, como ocurre con el plano cenital del plato de caldo en la secuencia del duelo.

\section{La estética como pasión y modernidad en la obra de Pedro}

\section{Almodóvar}

Cuando se estrena Pepi, Luci, Bom y otras chicas del montón, en 1980, Pedro Almodóvar ya lleva varios años difundiendo sus cortometrajes en los circuitos alternativos de un Madrid que intenta acabar con el clima gris del franquismo.

"Movida" es el término que se acuña para denominar estas manifestaciones artísticas y culturales que se producen en el Madrid de finales de los setenta, y en las que Pedro Almodóvar se integra como uno más. Por una parte, como ya se ha analizado, el cineasta manchego colabora con artistas plásticos integrados en la "movida", que comparten con él referentes estéticos e ideológicos. Sin embargo, existe otra coincidencia aún más básica entre la sensibilidad característica de este movimiento cultural y la concepción que Pedro Almodóvar manifiesta en su cine: la utilización creativa de motivos propios de la cultura popular de consumo masivo por parte de todos ellos supone la exaltación de la modernidad en la España del periodo.

Evidentemente, las manifestaciones artísticas que se dan en el Madrid de finales de los años setenta llegan con una década de retraso en relación con el desarrollo del pop en los Estados Unidos. Sin embargo, hay que considerar la novedad radical que supone esta separación de la denominada "alta cultura" que define la iconografía artística de la "movida": la conversión del cine, la prensa del corazón, los cómics o la televisión en objetos artísticos supone una 
ruptura con el panorama cultural propio del franquismo. Durante este periodo, los elementos provenientes de la cultura popular se habían utilizado para diluir la disidencia o se habían tratado de manera peyorativa. Sin embargo, los representantes de la movida, y Pedro Almodóvar con ellos, propician que lo popular se asimile a lo nuevo y se dignifique.

Todos estos elementos configuran un todo uniforme y resultan decisivos para singularizar el cine de Almodóvar. Mucho se ha hablado de la confluencia de referentes estéticos que se acumulan en la obra del director manchego. El más analizado de estos referentes es el uso de objetos cotidianos y de elementos propios de la iconografía de la sociedad de consumo que definen el movimiento pop. También se ha evaluado el elemento kitch presente en su obra, que el propio director define como "la glorificación del mal gusto de lo cotidiano elevado a la categoría de algo artístico"9.

Y, sin embargo, incluso en este momento, cuándo sus referentes estéticos estaban tan integrados en el contexto histórico, la obra del director manchego siempre manifestó una especificidad estética que todavía constituye uno de sus rasgos más característicos.

En principio, la estética de una película se define básicamente a través del decorado, el atrezzo y vestuario y la iluminación. Todos estos elementos tienen que apoyar las características de los personajes, contribuyendo a hacer más creíbles su clase social, su personalidad y motivaciones. Y, sin embargo, Almodóvar mantiene una estética muy marcada en casi todas sus películas, a pesar de que las características de sus personajes sean distintas de un guión a otro. La estética propia de este director ha ido evolucionando en la misma medida en la que han crecido los medios de producción con los que cuenta, y se ha matizado cuando los elementos propios del melodrama y la dimensión intimista de los personajes han ganado más peso en su obra.

La apariencia del universo almodovariano se fundamenta principalmente en el uso del color. El autor muestra una predilección por los colores saturados, especialmente colores puros, primarios y secundarios (rojos, verdes, azules,

$9 \mathrm{El}$ director se refiere concretamente a Laberinto de pasiones con este comentario (Citado en Maldonado, 1990: 89). 
amarillos, violetas, anaranjados). El color ocupa un papel predominante en el encuadre, en el que adquiere un gran peso visual. Suele aparecer en grandes áreas, aunque las telas de intensos estampados y los objetos de plástico de colores brillantes también son habituales en las películas del director manchego.

Pero, sobre todo, hay que destacar que el color tiene una función dramática básica para Almodóvar. Es imposible establecer reglas fijas que permitan decodificar estos códigos en las películas del director manchego, y, como un claro ejemplo, se puede mencionar la importancia metafórica que adquiere el blanco y negro en la película muda El amante menguante (Shrinking Lover $^{10}$ ). Un fragmento ajeno a la línea narrativa principal que se inserta en Hable con ella (Talk to her, 2002) que simboliza la relación entre dos de los personajes principales, Benigno (Javier Cámara) y Alicia (Leonor Watling). Pero aún con excepciones como ésta, el uso de los colores primarios suele ser un elemento privilegiado por Pedro Almodóvar en la transmisión de los sentimientos de los personajes y en la creación de atmósferas.

El rojo resulta especialmente relevante en los momentos de dolor y pasión que viven sus protagonistas femeninas. En Todo sobre mi madre (All About my Mother, 1999), Manuela (Cecilia Roth) está vestida de rojo cuando muere su hijo. Pepa suele ir igualmente vestida de rojo en Mujeres al borde de un ataque de nervios (Women on the Verge of a Nervous Breakdown, 1988), y rojos son también el teléfono del que espera una llamada de Iván (Fernando Guillén) y la flor que quema cuando está destruyendo o guardando los objetos que le recuerdan al hombre que la ha abandonado. Este personaje de Carmen Maura en Mujeres... suele repetir con frecuencia el gesto de pintarse los labios en un tono carmesí.

El uso de este mismo color había llegado al paroxismo en otra película anterior de Almodóvar, Matador (Matador, 1986). En esta historia en la que se mezclan elementos del thriller y del melodrama con unas pocas referencias a la comedia, María, la abogada obsesionada por la muerte, lleva

${ }^{10}$ Traducción literal del título de este corto, integrado en el metraje de Hable con ella (Talk to her, 2002) 
los labios pintados de rojo intenso, incluso cuando está ejerciendo su profesión. Y en esta misma película resulta muy significativo que el personaje de Eva (Eva Cobo), vestida de rojo, también se pinte los labios del mismo color en la secuencia en la que está sola esperando a Diego (Nacho Martín), su novio, despechada por el abandono de éste.

Y la pauta también se repite en Volver. En la secuencia en la que Raimunda conoce que Paula ha asesinado a su marido, Paco (Antonio de la Torre), el rojo es también el color dominante. El inicio de la secuencia es una mancha que llena toda la pantalla cuando un autobús de este color, filmado con un teleobjetivo de $140 \mathrm{~mm}$, pasa fuera de foco por delante de Paula. Inevitable evaluar también aquí una dimensión simbólica, por mucho que el propio Almodóvar se contradiga a este respecto ${ }^{11}$.

Queda claro que este uso del color se hace patente de manera significativa en el vestuario. Pedro Almodóvar siempre ha prestado mucha atención a la actividad de este departamento en sus películas. De hecho, el director está directamente implicado en la elaboración del vestuario y los decorados de sus obras hasta Matador. En estos momentos iniciales, la ropa de las "chicas Almodóvar" mezcla elementos procedentes de la cultura popular con rasgos indumentarios propios de corrientes contemporáneas. Y un claro ejemplo es el personaje de Bom (Olvido Gara, "Alaska”) en Pepi, Luci, Bom... que aparece vestida de acuerdo con la estética punk y lleva puestos los mismos pendientes que suele utilizar la mujer ataviada con uno de los trajes folclóricos andaluces, el de sevillana. La caracterización de Alaska en esta película también ilustra la manera en la que el director transforma la falta de refinamiento, la mezcla abrupta de estilos y de colores estridentes, en una marca característica. De hecho, aunque recibió muchas críticas que la calificaban como cutre y de mal gusto, esa estética fundamentada en el vestuario y en unos decorados concebidos de manera muy similar contribuyó

${ }^{11}$ En los comentarios que incluye en el DVD de la película, el director afirma que los personajes visten de rojo para que destaquen mejor en la oscuridad. Pero también es de noche cuando Raimunda se deshace del cadáver y, sin embargo, el personaje viste entonces con un chándal azul marino. 
decisivamente para que el cine de Pedro Almodóvar fuera inmediatamente reconocible por parte del público.

Pero Bom es sólo un ejemplo de que, en el cine de Almodóvar, el vestuario sirve a la vez para definir lo que los personajes son y lo que les gustaría ser. La ropa barata y de colores oscuros de Carmen Maura delata con crudeza la condición social marginal del personaje que interpreta en ¿Qué he hecho $Y O \ldots$ ! Los trajes de chaqueta años 60 que lleva Lucía, encarnada por Julieta Serrano en Mujeres..., son significativos de su pretensión de mantenerse en el pasado, cuando aún no había sido internada en el manicomio, ni había sufrido el abandono de su marido, Iván. El traje llega a ser, incluso, un acto de pasión para los personajes femeninos almodovarianos: en la secuencia del desfile de modelos de Matador, Assumpta Serna y Eva Cobo van ataviadas con dos creaciones de Francis Montesinos que reflejan con claridad a los dos personajes que interpretan. La primera de las actrices lleva un vestido transparente y una capa que imita el capote de un torero. Eva Cobo, por su parte, va ataviada con un modelo rojo, de talle largo, y color rojo sangre. Estos dos modelos, creados específicamente para la película, reflejan con claridad el enfrentamiento erótico de los dos personajes, que pugnan por el amor del matador, Diego. María, encarnada por Assumpta Serna, está obsesionada con la muerte, y es una asesina. Su capa también es símbolo de que ella se identifica con el toreo como ejercicio de pasión y de muerte.

Pero, aunque hay rasgos que se mantienen, lo mismo que otros aspectos de su obra, el uso de la moda que Almodóvar hace en las películas ha evolucionado de manera paralela a su universo personal. Además, el director ha alcanzado ya una situación en la industria del cine que le permite utilizar todos los medios de producción que desee. Su fama mundial ha contribuido para convertir sus obras en la pasarela ideal que cualquier diseñador desearía. Y, desde luego, suele ser frecuente que las actrices de Almodóvar utilicen vestuario elaborado por los mejores creadores: en Kika, por ejemplo, Victoria Abril va vestida por Jean Paul Gaultier, con trajes muy inspirados en la estética punk. En Tacones Lejanos (High Heels, 1991), esta misma actriz lleva dos trajes de Chanel y Marisa Paredes, que interpreta a Becky del 
Páramo, utiliza ropa de Giorgio Armani. Este mismo diseñador presta sus trajes de manera gratuita para el personaje de Rosa, interpretado por Rosa María Sardá, en Todo sobre mi madre. Según la responsable vestuario, Sabine Daigeler, gran parte de la ropa de las actrices que intervienen en esta última película es material proveniente de grandes marcas, entre las que también hay que contar a Galiano o Rochas ${ }^{12}$.

Sin embargo, resulta muy significativo lo distinta que es la concepción del diseño de vestuario en las dos obras de Almodóvar en cuyo equipo técnico estuvo integrada Sabine Daigeler. Una de ellas es Todo sobre mi madre, como ya se ha mencionado, y la otra es Volver. En esta última película, se incluyen unos pocos diseños de Mark Jacobs, Prada o Dolce \& Gabbana. Sin embargo, la mayor parte de la ropa de las actrices proviene de mercadillos de los barrios más populares de Madrid, como Vallecas. La vestimenta de Penélope Cruz, que interpreta el personaje de Raimunda, fue confeccionada expresamente para ella siguiendo las pautas estéticas de la ropa de mujer que se suele vender en este tipo de mercadillos ${ }^{13}$.

La orientación tan distinta de dos trabajos realizados por la misma diseñadora de vestuario demuestra que, para Almodóvar, la ropa debe estar en función de la psicología y de las circunstancias vitales de sus personajes. La moda proveniente de grandes diseñadores aparece en sus películas sólo si tiene una funcionalidad específica. Los responsables del diseño de vestuario trabajan en los figurines teniendo en cuenta únicamente la definición de estos aspectos en sus guiones, y que, evidentemente, cambian de una película a otra dependiendo de las características de cada personaje. Según Sabine Daigeler, Almodóvar sabe muy bien qué estilo quiere en el diseño de vestuario de cada película y concreta sus criterios en frecuentes propuestas sobre el tema ${ }^{14}$. Los responsables de vestuario, además de trabajar con unos colores muy vivos y una paleta no demasiado extensa, se enfrentan con otro desafío considerable en la labor que desarrollan para el director manchego:

\footnotetext{
${ }^{12}$ Entrevista a Sabine Daigeler, 19-IV-2007.

13 Idem.

14 Idem.
}

91 
diseñar una ropa que armonice con los decorados, en los que también suelen ser frecuentes los colores fuertes.

También el atrezzo y los decorados participan de esta estética almodovariana de colores saturados. El uso del atrezzo en la filmografía de este director destaca sobre el nivel medio de las películas españolas por el cuidado con el que está hecho. El diseño de este elemento pretende alcanzar un difícil equilibrio entre lo estético, lo naturalista, lo vulgar y lo grotesco, y siempre teniendo en cuenta de la paleta de fuertes colores marcada para cada película. En un esfuerzo paralelo al realizado por los responsables de vestuario para caracterizar a Penélope Cruz de manera sensual con ropa de mercadillo, los decorados de Volver se llenan de objetos cotidianos de colores vivos, como tupperwares de plástico rojo intenso o marcos de foto de plástico verde. Otro ejemplo es el destartalado y algo antiguo coche de Sole, que los personajes utilizan para ir y venir de su pueblo natal, y que está pintado con un hermoso y saturado rojo. Sin embargo, a veces, este compromiso entre la estética colorista de Almodóvar y el naturalismo desemboca en soluciones algo forzadas. Es el caso del decorado del restaurante de Volver, construido sobre un descampado en una localización natural de un barrio de Madrid. En los planos generales, se observa cómo los colores vivos del restaurante y el pequeño parque infantil adyacente, con un césped verde y cuidadísimo, resultan incongruentes con los edificios y los yermos descampados que los rodean.

Y de la misma forma que el decorado y el atrezzo participan de colorido tan especial, también sirven al director manchego para definir a sus personajes. Uno de los numerosos ejemplos ilustrativos, que aparece en Todo sobre mi madre, es el uso de muebles modernos y funcionales en el piso de Manuela en Madrid, que se contrapone con los variados objetos de cierto mal gusto que se acumulan en la casa de la transexual Agrado (Antonia San Juan) en Barcelona. La vida tranquila de la una y la peripecia vital desordenada de la otra se simbolizan con claridad en los espacios interiores que las identifican.

Retomando su último film Volver, resulta muy significativa la diferencia en el tratamiento, tanto en la forma como en los colores, del decorado de la casa de 
Raimunda con la casa de Sole, ambos construidos en un plató. La casa de Raimunda es el espacio interior en el que transcurren gran parte de las dificultades de la protagonista. Es un lugar más de thriller y de drama, donde se presenta al marido desempleado que mira el fútbol y bebe cerveza, en latas convenientemente amarillas y rojas, por cierto. Es aquí también donde ocurren el intento de violación y el asesinato, y donde Raimunda recibe las noticias de la muerte de Tía Paula. El espacio del decorado de esta casa es tortuoso, con abundantes tabiques que separan los espacios y con más pasillos, y tanto el color de las paredes como el atrezzo tienen una tonalidad más apagada y un aspecto más feo y realista que en el resto del film. Por el contrario, la casa de Sole es un espacio rectangular y más diáfano, sin separación entre el recibidor, el salón y la cocina, y donde las puertas están abiertas, favoreciendo así el juego actoral en diferentes espacios de profundidad de tipo vodevil de estas secuencias. Como el propio Almodóvar cuenta en los comentarios del director incluidos en el DVD, este es el espacio reservado en la película para la comedia, y tanto la forma como los colores, más fuertes y sobre una base de tonos naranjas, contribuyen a dar esta impresión. Se podría decir que, mientras la casa de Raimunda es un resumen elegante del feismo de Qué he hecho yo para merecer esto!, la casa de Sole está más emparentada con los coloristas decorados almodovarianos de los 90, en los que el naturalismo se distorsiona para privilegiar un resultado estéticamente fuerte y atractivo.

A pesar de la evolución patente en su filmografía, que se manifiesta, como ya se ha dicho, en el vestuario y en el decorado, hay una serie de constantes que se mantienen a lo largo de toda la filmografía de este director. Y una muestra de ello son los resultados estéticos similares que se han derivado de la colaboración de Almodóvar con técnicos profesionales muy distintos, tanto en decorados y vestuario como en fotografía ${ }^{15}$. Para desentrañar las

15 Pedro Almodóvar suele contar siempre con los mismos profesionales para las tareas técnicas. Paco Femenía, en Pepi, Luci, Bom y otras chicas del montón y Ángel Luis Fernández, luego, han sido los directores de fotografía elegidos por el director en sus primeros trabajos. Luego, Alfredo Mayo, Affonso Beato y, de forma repetida en los últimos años, José Luis Alcaine se han ido alternando en esta función. Javier Aguirresarobe fue el responsable del diseño de la luz en Hable con ella (2001). 
circunstancias que determinan este fenómeno tan poco habitual en cine actual, habría que analizar en profundidad el modo en el que Almodóvar se comunica y dirige a sus jefes técnicos. El director da alguna clave al respecto en otro de los pasajes de su diario de rodaje de Volver,

“Antes de comenzar cualquier película el director de fotografía me pide referencias, que sólo suponen un camino a seguir para encontrar tu propio camino. Normalmente yo les hablo de la fotografía de otras películas (suelo citar mucho a Jack Cardiff, pensando especialmente en las películas que hizo con Michael Powell ${ }^{16}$ ) o de pintores (acudo mucho a Edward Hopper y Zurbarán, además del pop) o le muestro imágenes que encuentro en revistas o libros" (ALMODÓVAR, 2006).

Precisamente, es el trabajo en fotografía e iluminación lo que contribuye definitivamente a crear esa estética tan propia del director manchego, que se plasma en los decorados, vestuario y atrezzo, pero no se define a través de la iluminación, que, por regla general, suele ser blanca y sin colorear. La luz en el cine de Almodóvar es bastante suave, homogénea y poco contrastada. Es frecuente que esta luz provenga de múltiples fuentes, lo que supone una tarea difícil para el director de fotografía, y que destacada poco sobre el conjunto del film si se compara con las tendencias actuales de fotografía cinematográfica. Es necesario realizar un trabajo muy serio y técnico para conseguir que los elementos saturados que tanto el departamento de vestuario como el de decorado sitúan en escenas se reproduzcan con esa tonalidad tan viva y definitoria del cine de Almodóvar. En este sentido, son significativas las declaraciones de Javier Aguirresarobe, un director de fotografía que se caracteriza por una personal y definida forma de entender la luz, con fuertes contrastes y densos negros, acerca de su labor en el film Hable con Ella:

“En esta película está la personalidad visual de Pedro Almodóvar en todos sus fotogramas. Y es eso lo que me gusta, porque creo que supe adaptarme a la estética que proponía el realizador. Hay un trabajo de luz que trata de

${ }^{16}$ La fructífera colaboración de Michael Powell con Jack Cardiff, director de fotografía y técnico pionero en el sistema Technicolor, abarca los melodramas A Matter of Life and Death (A vida o muerte, 1946), Black Narcissus (Narciso Negro, 1947) y el colorista musical The Red Shoes (Las Zapatillas rojas, 1948).

94 
preservar los ambientes naturales que propone la realidad. En la parte en blanco y negro quisimos amoldarnos al cine de época con un trabajo muy riguroso de cámara y luz.” (DEL RÍO, 2002).

José Luís Alcaine, director de fotografía y colaborador en cuatro películas de Almodóvar, resume así tanto el origen de la estética del director y su relación con la fotografía cinematográfica, y la evolución que esta ha experimentado desde su primera película juntos:

“[Pedro Almodóvar] ha evolucionado, se va a películas como más dramáticas, con menor tinte de comedia. Mujeres era una comedia y Pedro tenía una estética muy marcada por la época que transcurría, además el es un gran admirador de los años 50. Esos melodramas le hacían buscar la fotografía y el colorido de esas películas. Eso no es fácil de conseguir, porque la película era Technicolor, un color muy saturado, muy fuerte, porque era lo que se consideraba bueno. El proceso de laboratorio buscaba colores muy fuertes, y además de eso, la iluminación en esas películas era toda puntual. Eso era muy difícil de conseguir. En Mujeres está siguiendo ese tono; en Átame (Tie Me Up! Tie Me Down!, 1990) un poco menos, pero también está presente. En las dos últimas películas que he hecho con él ${ }^{17}$, Pedro ha experimentado una evolución y yo también. Hemos conseguido, de alguna manera, la cuadratura del círculo; hacer ese tipo de fotografía pero de manera más dramática. Ha sido una evolución mutua con respecto a este cine suyo. Estéticamente partimos de la base de que él quiere colores fuertes y muy limpios, y que se cuide mucho a las actrices. La historia que él cuenta tiene una vertiente dramática que de alguna manera se va acercando mucho a una naturalidad que no tenía cuando hicimos Mujeres".

En efecto, conseguir con los medios técnicos actuales el tipo de estética que se conseguía con el Technicolor es algo complicado, y que requiere una aproximación fotográfica y lumínica en cierto modo contraria a las tendencias fotográficas actuales de naturalismo y fuertes contrastes que apoyan el drama. El sistema Technicolor, al igual que el formato Scope, nacieron como una respuesta espectacular de la industria para atraer al público a las salas de cine, en aquel momento en competencia directa con la

${ }^{17}$ Se refiere a las películas La Mala Educación y Volver.

95 
televisión. Técnicamente, consistía en un sistema de prismas y espejos en el interior de la cámara, que conseguía separa en rodaje los colores rojo, verde y azul y exponerlos simultáneamente en tres rollos de película sensible. Estas tres bandas de imagen se unían en laboratorio, en un complicado proceso que privilegiaba la saturación y la espectacularidad de los colores. Con el sistema actual de Kodak, basado en una única película con tres capas sensibles superpuestas, se obtienen colores mucho más naturales, y resulta muy difícil imitar el resultado que se obtenía con el procedimiento Techicolor. ${ }^{18}$

La opción de Alcaine es fotografiar con una película de sensibilidad relativamente alta, sobrexponiendo un poco para conseguir una mayor densidad en el negativo que ayude a saturar los colores, y sin utilizar ni filtros en cámara ni mucho color en las luces para conseguir un aspecto lo más limpio posible. Se observa así cómo el director de fotografía sólo utiliza colores en las fuentes de luz cuando quiere dar una impresión lumínica de hora del día, pero del modo naturalista que caracteriza a Alcaine. Vemos así contraluces anaranjados en la casa de Sole, en aquellas secuencias que tienen lugar a primera hora de la mañana o a última de la tarde, o los tonos dorados del sol invernal de mediodía cuando está comiendo el equipo de rodaje en el restaurante de Raimunda, en un ejemplo de lo que el veterano operador denomina "luz de siesta”. Asimismo, también aparece algo de corrección de color en la iluminación de los interiores noche, donde para crear la ilusión de un espacio interior, se añade algo de amarillo a las lámparas de escena y algo de azul a la luz que entra por las ventanas.

En definitiva, Almodóvar elabora sus películas en torno a unos conceptos estéticos y narrativos muy propios, como son los colores saturados, la imagen pop, la apropiación de la narrativa de los melodramas clásicos norteamericanos y la oscilación, brusca a veces, entre el drama, la comedia y

18 En este sentido, el director Martin Scorsese realizó un profundo esfuerzo para reproducir con técnicas actuales los colores clásicos de Hollywood en su película The Aviator (El Aviador, 2004), mediante una costosa técnica de escaneo del negativo y manipulación por ordenador conocida como tablas LUT. Para más información, consultar la revista online de la American Society of Cinematographers. http://www.theasc.com/magazine/jano5/ aviator/ 
el costumbrismo pintoresco en una misma película. Aunque la conjunción de dichas características lleva a veces a que sus obras presenten un ritmo narrativo extraño y desigual, según los códigos de la ficción cinematográfica estándar, son los que definen al autor manchego. Están presentes en toda su filmografía, si bien es verdad que se puede apreciar una progresiva estilización de dichos elementos. Se podría aventurar, por lo tanto, que las pautas estéticas características en la obra del director manchego tienen mucho más que ver con su concepción personal que con el trabajo colectivo que implica la realización y difusión del cualquier obra cinematográfica.

\section{Referencias bibliográficas}

MOLINA FOIX, Vicente (1993). El cine estilográfico. Barcelona: Anagrama, 1993

D’LUGO, Marvin (2004). El extraño viaje alrededor del cine de Almodóvar. En Journal of Spanish Cultural Sutidies, Vol. 5, N. 3, p.295.

MALDONADO, T. (1990) La estética del cine de los ochenta”. En GARCÍA DE LEÓN, M.A. y otros, El cine de Pedro Almodóvar y su mundo. Madrid: Universidad Complutense de Madrid, p. 89.

ZURIÁN, F.A. (2005) Mirada y pasión. Reflexiones en torno a la obra almodovariana. En ZURIÁN, F. A. y VÁZQUEZ VARELA, C. (coords.). Almodóvar: el cine como pasión. Actas del Congreso Internacional Pedro Almodóvar, Cuenca, Ediciones de la Universidad de Castilla-La Mancha, p.28.

\section{Referencias digitales (en línea)}

ALMODÓVAR, Pedro (2006). Diario de rodaje de Volver. http://www.clubcultura.com/clubcine/clubcineastas/almodovar/ esp/diarioo1.htm

DURÁN, O. Volver, colorista y dramática. En Cameraman $\mathrm{n}^{\circ} 009$. http://www.cameraman.es/downloads/oog/48-51\%20volver.pdf

DEL RIO, PABLO (2005) Entrevista a Javier Aguirresarobe. En Cameraman $\mathrm{n}^{\circ}$ o01 http://www.cameraman.es/

\section{Otras fuentes}

Entrevista personal a Sabine Daigeler, diseñadora de vestuario (realizada en Madrid, el 19 de abril de 2007). 